\title{
Maintaining a Healthy Workforce
}

\author{
Jean Chow RN, RAc, PhD \\ Faculty of Health and Community Studies \\ Faculty of Continuing Education \\ Mount Royal University \\ Calgary, Alberta, Canada \\ chow_jean@hotmail.com \\ Ruth Kalischuk RN, PhD \\ Faculty of Health Sciences \\ University of Lethbridge \\ Lethbridge, Alberta, Canada
}

\author{
Particia M. Burrell, PhD, APRN, APMH CNS-BC \\ Department of Graduate, Undergraduate, and Post- \\ Baccalaureate Nursing Programs \\ Hawaii Pacific University, College of Nursing and health \\ Sciences \\ Kaneohe, Hawaii \\ pburrell@hpu.edu \\ Ann Longnecker RN, CNM and Lele Ah Mu RN, BN \\ Department of Nursing \\ American Samoa Community College \\ Pago Pago, American Samoa
}

\begin{abstract}
The study describes the health maintenance practices and utilization of complementary and alternative therapies by nurses and nursing students from Canada, Hawaii and American Samoa. Forecasts of an ongoing nursing shortage coupled with a focus on healthy behavior provided an impetus to describe actual practices of self-care and use of alternative therapies. The study addresses the dearth of knowledge in this area. Nurses and students were asked to anonymously complete a two-part survey that enumerated their perspectives on alternative therapies usage and self-care. Indicators of self-care included sleep, nutrition, exercise, and time. Use of alternative therapies is an integral part of self-care for the nurses and students in the three study regions.
\end{abstract}

\section{Keywords-self-care; life style; nursing students; nurses; health}

\section{INTRODUCTION}

It is widely acknowledged that nurses are the glue that holds the health care system together. Nurses' vital service to humanity is often ignored and not forefront in the business of health care. However, at this time, the lack of nursing personnel has become evident worldwide as the business of providing health care to people has encountered a deficit in nurses. From a business model perspective, nurses contribute to society by maintaining the health of societal members. Therefore, health care workers are needed to enable societal members to function economically, and to a large part, the business of health care needs to function adequately to ensure there are workers in society at large. Continuing the business model perspective, it is then clear that the availability of nurses is in part dependent on their well-being and that the well-being of nurses is heavily dependent on self-care measures. This paper examines nurses' self-care practices using selected markers such as nutrition, exercise, sleep, time spent on self-care, and complementary healing approaches.

The concept of self-care for nurses is a recent phenomenon; its importance for individual health and workplace retention has been over shadowed by the allure of the business model. The need for nurses in any particular setting is determined by the mathematical stipulations that do not account for the complexity and chaos in care [4]. It is interesting that in capitalist ideology, the economy appears primary while the secondary, more human directed issues are social and cultural. In relation to this paper, the meaning rests with what counts and what counts for the economy is that nurses are present for work. In addition, women who are nurses are often expected to perform a double-shift whereby they perform their work duties in both the public and private spheres. The capitalist market enforces the use of individuals and their labour and through exploitation, one party benefits from the efforts of another.

Many times, the exploitation comes from nurses themselves. The call of duty to the other (patient/client) supersedes the call of duty to the self. "The patient comes first" as meal breaks are missed, nurses are called back to work with little rest, or work overtime and the list goes on. Nurses may be placed on permanent night shifts even when they do not provide consent. However, to refuse may mean loss of employment, income and financial well-being. It is common to hear how patient loads can lead to nurses missing rest and meal breaks. Exhaustion in health care settings is a workforce issue. In the 1990's and the early 2000,'s there were accounts of nurses dropping dead while working. In Japan, the phenomenon is called "Karoshi" while in China, it is called "Gaolaosi" [2, 14]. In a field in which most of the employees in nursing are women, nurses may suffer from exploitation. Women's lives and bodies are influenced by social norms and responsibilities that affect and are affected by the political economy [5].

At the side-lines, out of sight of business analysis, is what keeps life humane; the nurse either knowingly devotes time to renew self or neglects the self to some degree. The employee may grow weary from being over-worked, however the worker "must be able to work on the morrow with the same 
amount of force, health and freshness as to-day" [3, p. X-337]. Self-renewal for nurses needs dedication.

While nurses care for patients and clients, it can be argued that attention needs to be highlighted on the care for nurses. While nurses are guided by theory and nursing ideology to focus on health promotion for the other, it is clear that selfadoption of such practices requires more emphasis and that the nurse should care for self by engaging in activities that promote well-being. Explicitly, nurses need to integrate what is learned from their education, and known from their social and/or cultural contexts to maintain and promote health. It is assumed that to be able to provide client care, the nurse needs to provide some attention to self. Nurses cannot provide care if they themselves are not functioning within the manifold dimensions of the model of holism. Therefore, deficiencies in any dimension of the Engel's biopscyhosocial model [1] can preclude the nurse from providing good care or caring excellence. Caring excellence occurs when the nurse is supported in efforts to genuinely use the "self" to aid individuals, teams, and communities [11,12]. Van Manen [19] captures the linkages that influence one's well-being with an eloquent statement. "Caring for others is difficult if not impossible if, in an obvious as well as a deeper sense, one's own house is not in order, so to speak" [19, p. 267]. Therefore in its application to nurses, when the nurse's own house (the self) is not in order, it is difficult to care for others.

In nursing work, without proper attention to self, a nurse can insidiously become unhealthy. For example, the energetic output of worry from the nurse can ultimately affect the self.

"Care-as-worry is like an illness, a chronic illness. Incurable. Untreatable. It may have its easy periods when it seems to go into remission, but then it flares up again, especially in cases of caring for a child in difficulty, sickness, or in trouble but also in ordinary situations where choices of consequence need to be made. The parent who is possessed by this caring response to his or her child cannot help but suffer this illness.[19, p. 265]."

Even though van Manen [19] specifically referred to the care of children, the same ideas can be transferred to patient care. Nurses worry. It is part of their care and they sometimes carry the worry home.

Although the nursing shortage is not a new phenomenon; shortages have occurred in cycles and by region [10]. The current demand for nurses is increasing due to an aging population, increased population growth rates, and increased chronic and communicable diseases. The supply of nurses is decreasing in some regions and expected to worsen with the aging workforce, alternative career choices, and the lack of political will to address issues that impact nurses. Given the information about the state of nursing worldwide in terms of shortages, the question arose about the care nurses provide themselves to maintain their own well-being. In addition, the question arose about the use of healing modalities for selfcare.
Currently, complementary and alternatives, complementary medicine, alternative medicine, and integrative medicine are promoted widely to the public [13]. NCCAM recognizes that each of these labels can be difficult to define and people may have different meanings for terminology although the labels are often used to portray health care approaches or a history of use that are outside of mainstream medicine. Complementary medicine describes the use of non-mainstream medicine with conventional medicine. Alternative medicine is the use of non-mainstream medicine in place of conventional medicine. The field is changing continually as the margins of complementary and conventional medicine overlap. Massage was once considered as complementary and is now being utilized within hospital settings. The label that NCCAM currently employs for complementary and alternative medicine (CAM) in its research is complementary health approaches.

Complementary health approaches are often grouped into two broad categories, which includes natural products and mind and body medicine. Vitamins and minerals are examples of natural products. Massage, spinal manipulation, and yoga are examples of mind and body practices.

\section{STUDY PURPOSE}

To determine the level of self-care engagement by nursing personnel and students, research focused on the practice of self- care took place in North America and the Pacific islands. The paper brings together three studies about self-care and the use of complementary health approaches by nursing students and personnel. An initial survey was completed by nursing students in Canada and a refined survey was used in Hawaii and American Samoa to collect data.

After ethical approval was obtained from each of the study settings, the survey was distributed to the study population by instructors or research staff. Participants completed the survey on a voluntary basis. If individuals did not wish to complete the questionnaire, they left it blank or refused to accept the survey. Completed surveys were collected by the instructors and research staff. The collected survey data were entered into SPSS (Statistical Program for the Social Sciences) and analyzed using descriptive statistics.

\section{SAMPLE AND SURVEY}

Two hundred and eleven nursing students from a Canadian baccalaureate nursing program and another 81 nursing students and instructors were recruited from a baccalaureate nursing program located in Hawaii. In American Samoa, 60 Registered Nurses (RNs), Licensed Practical Nurses (LPNs), nursing students, and LPN students from the hospital and college took part in the study. The sample comprised of 16 RNs, 34 LPNs, seven RN students and three LPN students. A total of three hundred and fifty-two participants took part in the three studies.

The survey gathered data about current self- care strategies and perceptions about complementary health approaches. The initial survey consisted of closed and open ended questions. 
The three part survey consisted of questions about self-care, use of complementary health approaches, and demographics. The refined survey used in Hawaii and American Samoa consisted of 32 questions about self-care and 11 questions about complementary healing approaches. In the self-care section of the survey, participants were asked about nutrition, sleep, hydration, medical visits, and perceptions of wellness. The questions about complementary health approaches were related to complementary therapy usage, knowledge about complementary health approaches, satisfaction with the therapies, and perceptions about the effectiveness of the therapies. Using the categories from the Canadian study, selfcare activities were broadly grouped into meeting daily needs, health promotion activities, and engagement in health and healing modalities [6]. These capacities were regarded as measures of self-care activities. In this paper, the focus will be on sleep, nutrition, exercise, use of complementary health approaches, and the time spent on self-care activities.

\section{RESULTS}

\section{A. Meeting daily needs and health promotion activities}

The self-care activities classified as meeting daily needs were sleep and nutrition.

1) Sleep and nutrition. The mean number of hours for sleep was reported as 6.7 hours and most of the students (83\%) slept between 6-8 hours. Sixty percent of the nursing studentsindicated that they had adequate sleep and 39\% indicated that they did not sleep enough. In American Samoa, $55 \%(n=33)$ of the participants reported inadequate sleep and $40 \%(n=23)$ reported adequate sleep. In Hawaii, 46\% $(n=37)$ of the participants reported adequate sleep while $51 \%(n=42)$ reported inadequate sleep.

Adequate nutrition contributes to well-being. The majority of Canadian participants indicated that they ate what they considered to be a balanced diet consistently $(28 \%, \mathrm{n}=58)$ or frequently $(49 \%, n=103)$. Another $23 \%(n=49)$ indicated that they rarely ate what they considered to be a balanced diet. In American Samoa, 5\% $(n=3)$ of the participants perceived that they consistently ate a balanced diet, $32 \%(n=19)$ perceived that they frequently ate a balanced diet, $53 \%(n=31)$ rarely ate a balanced diet while $10 \%(n=6)$ did not eat a balanced diet at all. In Hawaii, 57\% ( $n=46)$ of the students and instructors considered that they consumed adequate nutrition and had balanced diets, while $43 \%(n=35)$ of the participants indicated that they did not consider that they ate nutritious meals.

2) Physical Activity. Exercise is an example of a health promotion activity. In Canada, the majority of the study participants exercised occasionally $(44 \%, n=93)$ or consistently (27\%, $\mathrm{n}=57)$. In addition, $25 \%(\mathrm{n}=52)$ exercised rarely, and $4 \%(n=8)$ did not exercise at all. Exercise was not perceived as important in American Samoa by the nursing personnel and students. The majority $(50 \%, \mathrm{n}=30)$ rarely exercised and $18 \%(\mathrm{n}=11)$ did not exercise at all. Another $20 \%$ occasionally exercised and only $10 \%$ exercised consistently. In Hawaii, 14\% $(n=11)$ participants reported engaging in enough exercise, while $86 \% \quad(n=70)$ reported inadequate exercise.

\section{B. Use of Complementary Health Approaches}

The use of complementary health approaches can contribute to the maintenance of health. In Canada, the majority of the students $(76 \%, n=160)$ reported that they used complementary health approaches. Students were asked to list which complementary health approaches they used. The frequently used complementary health approaches included massage $(n=113)$, vitamins $(n=104)$, chiropractic $(n=52)$, herbal medicine $(n=51)$, yoga $(n=45)$, aromatherapy $(n=39)$, meditation/prayer/visualization $(n=33)$, and acupuncture $(n=19)$. Less frequently used modalities icluded homeopathy $(\mathrm{n}=10)$, naturopathy $(\mathrm{n}=8)$, reflexology $(\mathrm{n}=4)$, and hypnosis/self-hypnosis $(\mathrm{n}=4)$.

In American Samoa, 69\% ( $n=37)$ of participants did not report using any complementary health approaches while $32 \%$ $(n=17)$ used some modalities and $10 \%(n=6)$ did not provide any response. As in Canada, the majority of participants used massage (14) and vitamins (5). Other participants used herbs (3), meditation (3), and aromatherapy (1).

In Hawaii, $76 \%(n=61))$ students and instructors reported using complementary health approaches. Massage was at the top of utilization list with 50 (62\%) people, followed by vitamin usage $(51 \%, \mathrm{n}=41)$, and prayer $(51 \%, \mathrm{n}=41)$. Aromatherapy and meditation were both used by $9 \%(n=7)$ of the study participants. Sixty-two people $(n=50)$ reported satisfaction with the use of complementary health approaches.

\section{Time set aside for self-care}

In order to engage in self-care activities, nurses need to set aside time on a regular basis. In response to a question asking about time, the participants indicated the amount of time they engaged in self-care activities each day. In Canada, the mean number of minutes spent daily on self-care was 68.5 minutes, with $57 \%$ of the students indicating between 60 and 120 minutes, and $22 \%$ of students indicating between 30 and 60 minutes.

Fifty-two of the 60 participants in America Samoa responded to the question about time spent on self-care on a daily basis; $39 \%(\mathrm{n}=20)$ spent less than 60 minutes and $27 \%$ $(n=14)$ spent more than 60 minutes, 21\% $(n=11)$ spent more than 120 minutes, and $(13 \%, \mathrm{n}=7)$ spent more than 180 minutes.

In Hawaii, $68 \% \quad(n=30)$ of the participants spend 60 minutes or less per day in self-care activities. Thirty-two percent $(n=14)$ respondents spend over 60 minutes in self-care. Time for self-care for all study participants may be limited by employment, family, and academic commitments [6].

\section{$\mathrm{V} \quad$ DISCUSSION}

Health promotion consists of self-care, mutual aid or the ways people take to help each other, and healthy environments which is creation of settings conducive to health [8]. Self-care 
consists of the decisions and actions a person takes for health. Six areas for self-care include physical, mental, emotional, spiritual, relationships, and choice [7]. In translation of these areas into daily life, self-care involves choosing behaviours such as exercise, food, eating nutritious food, adequate rest, and using complementary healing approaches [15]. The selfcare activities reported in this study were collected without formal teaching, integration or prompting about self-care in the nursing programs or work settings. The study population included students, clinical personnel, and educators from three diverse geographical locations. . Using the measures such as sleep, nutrition, exercise, use of complementary health approaches, and time used to foster self-care, it can be concluded that nursing personnel and students can improve their self-care activities. In all three settings, participants reported inadequate sleep (Canada 39\%, American Samoa $55 \%$, and Hawaii, 51\%). Reporting on nutrition varied across settings. In Canada, $28 \%$ of the participants ate what they considered to be a balanced diet, $5 \%$ of participants in American Samoa ate a balanced diet, while $57 \%$ of participants in Hawaii considered that they ate a balanced diet. Physical exercise is important for overall health and wellbeing. Participant responses to their involvement in exercise indicated that engagement in exercise could be improved across all three settings. In Canada, $27 \%$ of the students indicated that the exercised consistently and $25 \%$ rarely exercised. In America Samoa, 50\% of the participants rarely exercised and $18 \%$ did not engage in any exercise. Eighty-six percent of the participants in Hawaii indicated that exercise was inadequate.

The amount of time spent on self-care is individual; the Canadian participants reported an average of 68.5 minutes for daily self-care activities. In American Samoa, 39\% of the participants reported spending less than 60 minutes per day on self-care. In Hawaii, $68 \%$ of the participants reported devoting less than 60 minutes per day on self-care endeavours.

The use of complementary therapy by the research participants indicates an existing knowledge base about complementary therapies and experience with the use of alternative healing modalities. Seventy-six percent of participants in Canada and Hawaii reported utilizing complementary healing approaches for self-care. Only $32 \%$ of the participants in American Samoa reported using complementary therapy. The types of complementary healing approaches used by the participants varied widely but in all three research settings, massage and vitamin use ranked as primary. In mainstream medical settings, integrative medicine or integrative health care encompasses the non-mainstream health care approaches [13]. NCCAM reports that the trend to using complementary health approaches is happening now. Increasingly health care providers and health care systems are employing complementary health approaches, and that this trend is occurring even though there is limited evidence for decision making.

Lack of self-care for nurses is a disturbing phenomenon. There needs to be emphasis on attending to self before attending to others. "If one does not appreciate the self as a caring person or if the nurse does not care for self, it is impossible for her to compassionately care for others" [17, p. 250]. Content in nursing education programs need to place emphasis on self-care for nursing personnel to foster long term professional viability. In the work setting, the conditions and environment conducive to health need to be created [8].

How do nurses advise clients in self-care when they do not follow participate themselves? They often expect patients to follow their health advice. There are occasions when nurses marvel at patients/clients who make the changes that are needed to achieve health and healing. Van Manen [18] writes of such moments as epiphanies. "Epiphany means that the text [life, ones child/family] must bring about a transformative effect so that its deeper meaning makes an edifying appeal to the self of the reader. Epiphany refers to the sudden perception or intuitive grasp of the life meaning of something" [18, p. 364]. The epiphany brings about a change. Nurses have knowledge obtained from nursing programs, books, and articles about diet, exercise, rest, and health promotion. However, as models of health and client/patient teachers, some health care providers need to improve on self-care activities. There is an assumption that if nurses or any other people for that matter, are healthy, then there will be a healthy workforce that assists in maintaining a prosperous society.

The nursing shortage is a symptom of a wider health system or societal ailment (Buchan \& Calman, 2004) in which self-care (or lack thereof) in nurses plays a major part. The shortage stems from an under valuation of nursing as women's work and the limited access to resources that would facilitate nurses in their work and careers. While individual nurses can be mindful of their health, policy changes are required that recognize the intensity of nursing work and shift work and use nursing resources effectively [4]. The numbers of available nurses is only part of the picture. The profession of nursing has the potential to create wide-reaching changes in the health care system [9] and nurses can facilitate change and lead by role modeling self-care behaviours.

\section{Implications}

Health promotion activities need to be encouraged and provided to nursing staff/students in a proactive manner. The notion of self-care may alleviate the nursing shortage to some extent in the long run, contain health care costs, and support making health a personal responsibility. A report from the National Institute on Aging notes several trends that with the predicted decrease in young people in the workforce, coupled with the increase in seniors around the world, and the shortage of nurses around the world, focus on the maintenance of a healthy workforce must be a major thrust worldwide [16].

\section{REFERENCES}

[1] Alonso, Y., "The biospychosocial model in medical research: the evolution of the health concept over the last two decades. Patient Education and Counseling, 53, 239 $244,2004$. 
[2] Anders, R. and Kanai-Pak, M., "Karoshi and the Japanese nursing shortage." Nursing and Health Care, 13(4): 186$191,1992$.

[3] Aveling, E.B., Marx, E.B., Engles, F., \& Moore, S Capital: A critique of political economy. London: Electric Book Company, 2001.

[4] Buchan, J., \& Calman, L. The global shorage of Registered Nurses: An overview of issues and actions. Geneva: International Council of Nurses, 2004.

[5] Butler, J., Gender trouble: Feminism and the subversion of identity. Routledge: Oxford, 2006.

[6] Chow, J., \& Grant-Kalischuk, R., "Self-care for caring practices: Student nurses' perspectives." International Journal for Human Caring, 12(3), 31-37, 2008

[7] Dossey, B.M., \& Keegan, L., Holistic nursing: A handbook for practice (6th ed.). Burlington, MA: Jones \& Bartlett Learning, 2013.

[8] Health Canada, Achieving health for all: A framework for health promotion, Ottawa: Author, 2004. Retrieved from www.hc-sc.gc.ca/hcs-sss/pubs/system-regime/1986frame-plan

[9] Institute of Medicine, The future of nursing: Leading change, advancing health. Washington, D.C.: National Academies Press, 2011.

[10] International Council of Nurses/Florence Nightengale International Foundation (ICN/FNIF), The global nursing shortage: Priority areas for intervention. Geneva: International Council of Nurses, 2006.

[11] McSherry, R., Pearc, P., Grimwood, K., \& Mcsherry, W. "The pivotal role of nurse managers, leaders and educators in enabling excellence in nursing care," Journal of Nursing Management, 20(1), 7-19, 2012.

[12] Miller, J.F., "Factors influencing excellence in nursing," Pennsylvania Nurse, 68(1), 4-9, 2013.

[13] National Center for Complementary and Alternative Medicine (NCCAM), "Complementary, alternative, or integrative health: What's in a name,?" Retrieved from http://nccam.nih.gov/health/whatiscam, 2013

[14] O’Neill,R,'Dropdead,'Retrievedfrom http://www.hazards.org/workedtodeath/dropdead.pdf , 2003

[15] Richards, K. (2013). Self-care is a life long journey. Nursing Economics, 31(4), 198-20

[16] Seniorjournal.com., "Nine trends in global again present challenges, says "U.S. study." Retrieved from http://seniorjournal.com/NEWS/SeniorStats/2007/7-0316-NineTrends.htm, 2007.

[17] Turkel, M.C. \& Ray, M.A., "Creating a caring practice environment through self-renewal." Nurs Admin Q, 28(4), 249-254, 2004.

[18] Van Manen, M., "From meaning to method." Qualitative Health Research, 7(3), 345-369, 1997.

[19] Van Manen, M. "Care-as-worry, or "don't worry, be happy.” Qualitative Health Research, 12, 262-277, 2002. 